\title{
Tobacco Exposed Buccal Mucosa Graft-A Potential Carcinogen for Scrotal Cancer
}

\author{
Chaitanya H. Raut, Atul Kumar, Fanindra Singh Solanki, Shabbir Hussian, \\ Deepti B. Sharma*, Dhananjay Sharma\# \\ Department of Surgery, NSCB Medical College, Jabalpur, India \\ Email: ${ }^{*}$ sharmadeepti3@rediffmail.com
}

Received May 25, 2011; revised November 23, 2011; accepted December 13, 2011

\begin{abstract}
Squamous cell carcinoma of scrotum is not common. It was the first cancer directly associated with a specific occupation i.e. chimney sweeps. We report a case of squamous cell carcinoma of scrotum developed in a patient of stricture urethra with multiple perineal urinary fistulas treated with lay open urethra with buccal mucosal graft. Tobacco exposed buccal mucosa graft can act as a carcinogen for scrotal cancer in patients with multiple fistula and poor hygiene.
\end{abstract}

Keywords: Buccal Mucosa; Scrotal Malignancy; Tobacco

\section{Introduction}

We report a case of squamous cell carcinoma of scrotum developed in a patient of stricture urethra with multiple perineal urinary fistulas treated with lay open urethra with onlay buccal mucosal graft.

\section{Case History}

A 45 year old Indian male, tobacco chewer since last 20 yrs, had presented with Balanitis Xerotica Obliterance changes of glans and long segment stricture $(5 \mathrm{~cm})$ of anterior urethra with multiple $(\mathrm{n}=3)$ urinary fistulae in the perineum and scrotum following incision and drainage of a perineal abscess 4 months back by some general practitioner. Histology of tissue scraping from fistulous tract showed chronic inflammation. He was treated in our institution with excision of fistulous tracts, perineal urethrostomy with lay open of anterior urethra and buccal mucosal grafting. Buccal mucosa graft was placed beside the whole length of laid open urethra and its margin was sutured to urethral margin. Patient was discharged with future plan for tubularization in second stage.

Patient lost to follow up and presented after six months with growth on the right side of scrotum. It was a fungating ulcero-proliferative growth of $10 \mathrm{~cm} \times 7 \mathrm{~cm}$, arising from the lateral margin of the buccal mucosa graft involving skin of the right hemiscrotum, fixed to the underlying structures, and extending up to the base of penis and left hemiscrotum (Figure 1). There were firm, mobile inguinal lymph nodes (horizontal chain) on the right side.

${ }^{*}$ Corresponding author.
Hemogloblin was $9 \mathrm{~g} / \mathrm{dl}$ and rest blood profile was normal. He was non diabetic and seronegetive for HIV. Biopsy showed well differentiated, keratinizing squamous cell carcinoma (Figure 2).Total scrotectomy, placement

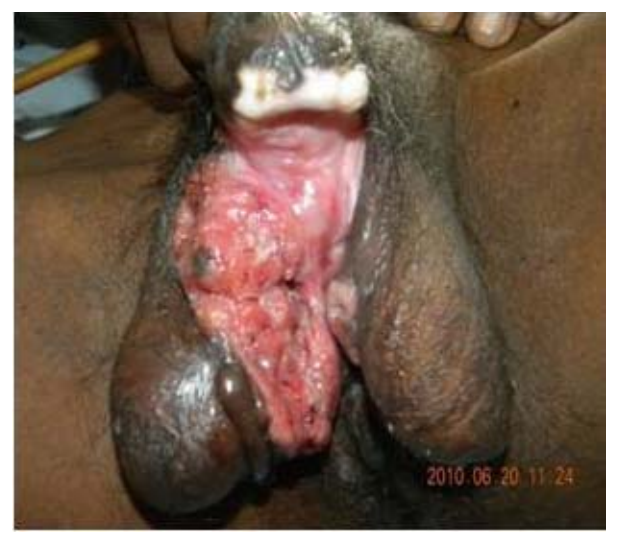

Figure 1. Scrotal tumor.

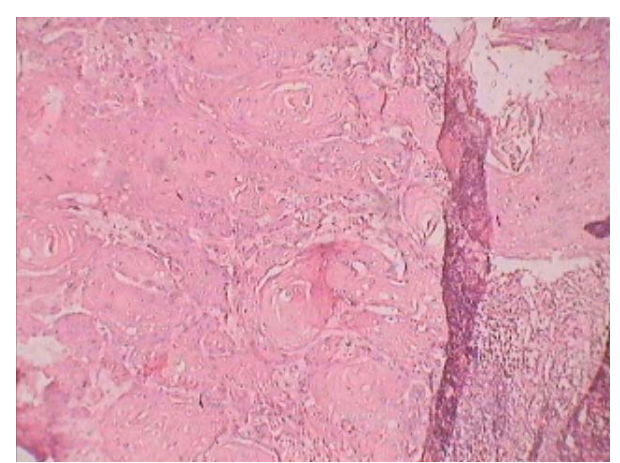

Figure 2. H \& E stain squamous cell carcinoma. 
of testis in medial thigh pouch, with total penectomy and a permanent perineal urethrostomy was done. Bloc dissection of bilateral inguinal lymph nodes was done one week later, showed mild hyperplastic squamous epithelium. Post operative period was uneventful.

\section{Discussion}

Squamous cell carcinoma of scrotum is not a commonly seen malignancy (incidence-1-5/100,000 person/year) [1], but it has been a topic of historical interest as it was the first cancer directly associated with a specific occupation, i.e. chimney sweeps [2]. Other etiological factors include exposure to environmental carcinogen like tar, paraffin, petroleum products [3] and machine oil [2], chronic irritation secondary to fungal infection and poor hygiene in old healed scar of Fournier gangrene [4]; UV rays, HPV6 virus, Psoralene for treatment of psoriasis [5]. Better personal hygiene, and the awareness of occupational exposure has led to dramatic decrease in incidence of scrotal cancer in US in past 50 yrs [6].

Buccal mucosa graft harvested from oral cavity and its use as dorsal onlay graft is gold standard procedure for management of complicated urethral strictures. It provide stable long term result with $25 \%$ complications including local like fistula, graft infection, necrosis and donor site complications like lip scar, transient lip motility impairment [7]. There is no reported incidence of malignancy in buccal mucosa graft placed at perineum.

Our patient was previously suffered from multiple perineal fistulas which is consider as important etiological factor for carcinoma scrotum although previous histological picture of tissue of fistulous tract showed chronic inflammation.

Buccal mucosa malignancy is very common in tobacco chewers. There was no evidence of malignancy in oral cavity in this patient when graft was taken.

It is more likely at least partially related that malignancy develop at potential risk places when exposed to more than one etiological factors. The patient had the history to link with main, contributory risk factor for carcinoma scrotum.

\section{Conclusions}

This gave rise to the conjecture that buccal mucosa constantly exposed to tobacco previously, may be the etiological factor in origin of this malignancy. Similarly it may be worthwhile to histopathologically examine every graft of buccal mucosa (to be used for urethroplasty) in patients who have long standing history of tobacco chewing (which is very common in India).

We recommend further study to evaluate the prognosis of carcinogen exposed structure when we use them as graft to other areas.

All authors of this manuscript do not have to disclose any financial relationship with a biotechnology manufacturer, a pharmaceutical company, or other commercial entity that has an interest in the subject matter or materials discussed in the manuscript.

\section{REFERENCES}

[1] R. H. A. Verhoeven, W. J. Louwman, E. L. Koldewijn, T. B. J. Demeyere and J. W. W. Coebergh, "Scrotal Cancer: Incidence, Survival and Second Primary Tumours in the Netherlands Since 1989,” British Journal of Cancer, Vol. 103, No. 9, 2010, pp. 1462-1466. doi:10.1038/sj.bjc.6605914

[2] A. H. Southam and S. R. Wilson, "Cancer of the Scrotum: The Etiology, Clinical Features, and Treatment of the Disease," British Medical Journal, Vol. 2, No. 3229, 1922, pp. 971-973. doi:10.1136/bmj.2.3229.971

[3] C. Presti Joseph, “Genital Tumor,” Chapter 23, In: A. Tanagho Emil and W. McAninch Jack, Eds., Smith General Urology, 17th Edition, Tata McGraw Hill Publishing Company, Noida, 2008, p. 387.

[4] K. Sanjeev, M. Sanjeev, P. Stephen, C. Sameer and W. Peter, "Unusual Squamous Cell Carcinoma of the Scrotum Arising from a Well Healed, Innocuous Scar of an Infertility Procedure: A Case Report," Annals of the Royal College of Surgeons of England, Vol. 89, No. 5, 2007, p. 548.

[5] G. Chatora, T. Rourke, N. Sezhian and G. Suresh, “A Case of Scrotal Cancer with Inguinal Lymph Node Metastasis Treated by Multidisciplinary Modalities: A Case Report,” International Journal of Urology, Vol. 4, No. 2, 2007,

[6] C. Antonio and C. Alcides, "Neoplastic Lesions of Scrotum Squamous Cell Carcinoma of Scrotum,” Accessed on 21 December 2010.

http://www.pathologyoutlines.com/topic/penscrotumscrotalSCC.html

[7] J. Fichtner, D. Filipas, M. Fisch, R. Hohenfellner and J. W. Thüroff, "Long-Term Outcome of Ventral Buccal Mucosa Onlay Graft Urethroplasty for Urethral Stricture Repair,” Urology, Vol. 64, No. 4, 2004, pp. 648-650. doi:10.1016/j.urology.2004.05.011 